http://www.jfas.info

\title{
NON-IONIZING RADIATION AS THREAT IN DAILY LIFE
}

S. K. F. Syaza ${ }^{1}$, R. Umar ${ }^{1, *}$, S. N. Hazmin ${ }^{2}$, M. K. A. Kamarudin ${ }^{1}$, A. Hassan ${ }^{3}$ and H. Juahir ${ }^{1}$

${ }^{1}$ East Coast Environmental Institute, Universiti Sultan Zainal Abidin, 21300 Kuala Nerus, Terengganu, Malaysia

${ }^{2}$ School of Fundamental Science, Universiti Malaysia Terengganu, 21030 Kuala Terengganu, Terengganu, Malaysia

${ }^{3}$ Institute for Community Development and Quality of Life, Universiti Sultan Zainal Abidin, 21300 Kuala Nerus, Terengganu, Malaysia

Published online: 08 August 2017

\begin{abstract}
Electromagnetic field (EMF) is a field of combination between electric and magnetic field. While electromagnetic radiation (EMR) can be divided into ionizing and non-ionizing radiation (NIR). This article review of published scientific studies about NIR and its effect on the human body. From this review, it is found that NIR gives effect towards the human body if it is exposed towards NIR in long time exposure. NIR also creates a thermal effect in long time exposure. This paper tends to create awareness for public that non-ionizing radiation provide an adverse effect towards public since its source is within our everyday life. For future study, we suggest for a policy to be applied in Malaysia as a basic guideline for EMR exposure and an implementation of mapping for EMR exposure at East and West of Malaysia to create an easiness for future researcher do a research in the EMR field study.
\end{abstract}

Keywords: electromagnetic field radiation; non-ionizing radiation; EMR.

Author Correspondence, e-mail: roslan@unisza.edu.my

doi: http://dx.doi.org/10.4314/jfas.v9i2s.21 


\section{INTRODUCTION}

Nowadays, the public are prone towards hazardous environment. It may come from pollutants such as air, soil, water and even electromagnetic wave. Electromagnetism is a combination of electric and magnetic field that can be easily found in our everyday life. It comes in a variety of frequency range. From extremely low frequency to the highest possible frequency. There are two types of electromagnetic waves in term of radiation which are ionizing and non-ionizing radiation.

Non-ionizing radiation is in the range of $0 \mathrm{~Hz}$ to $1015 \mathrm{~Hz}$. While, ionizing radiation is in the range of $1016 \mathrm{~Hz}$ up to $1026 \mathrm{~Hz}$. Table 1 shows the presentation of frequency of electromagnetic radiation.

Non-ionizing radiation comes from extremely low frequency (ELF), very low frequency (VLF), radio waves, microwaves, infrared radiation and visible light. Advancements in innovation and industry have improved human life. Be that as it may, presentation to electromagnetic fields (EMFs) by utilizing electrical machines, apparatuses, modern instruments, electrical cables and specialized gadgets has happened as a consequence of these mechanical advancements and is bringing about a risk to typical lives [1]. The nearest fast and so close technologies in our everyday life is a mobile phone.

Ionizing radiation is a well-known type of radiation that will give harm to the human body as it can ionize cell body in a second. Non-ionizing radiation can penetrate but have no enough energy to ionize an atom molecule of the human body. But, long time exposure can lead it give harm to the human body as its exposure is one of the important factors for an EMF to react with human body [2]. Many researchers agree that adverse non-ionizing radiation contributes towards hazardous for public [3]. A term used in referring towards potential health effects of EMF is electromagnetic pollution [4]. 
Table1. Presentation of frequency of electromagnetic radiation [5]

\begin{tabular}{|c|c|c|}
\hline Frequency/Wavelength & Type of Radiation & Sources \\
\hline $0 \mathrm{~Hz}-300 \mathrm{kHz}$ & $\begin{array}{l}\text { Low frequency to } \\
\text { extremely low frequency } \\
\text { (LF-ELF) } \\
\text { electromagnetic radiation }\end{array}$ & $\begin{array}{l}\text { Electrical fields of devices, } \\
\text { conventional electrical network, } \\
\text { video monitors, sections of AM } \\
\text { radio }\end{array}$ \\
\hline $3 \mathrm{kHz}-300 \mathrm{MHz}$ & Radio frequencies (RF) & $\begin{array}{l}\text { Sections of AM radio, FM radio, } \\
\text { medical short-wave, nuclear } \\
\text { magnetic resonance (NMR) }\end{array}$ \\
\hline $300 \mathrm{MHz}-300 \mathrm{GHz}$ & Microwave (MW) & $\begin{array}{l}\text { Domestic microwave devices, } \\
\text { mobile telephones, microwave for } \\
\text { medical physical therapy, radar and } \\
\text { other microwave communications }\end{array}$ \\
\hline $300 \mathrm{GHz}-780 \mathrm{~nm}$ & Infrared (IR) & $\begin{array}{l}\text { Solar light, heat and laser therapy } \\
\text { devices }\end{array}$ \\
\hline $780 \mathrm{~nm}-400 \mathrm{~nm}$ & Visible light & Solar light, phototherapy, laser \\
\hline $400 \mathrm{~nm}-100 \mathrm{~nm}$ & Ultraviolet (UV) & $\begin{array}{l}\text { Solar light, fluorescent tubes, } \\
\text { food/air sterilization, radiotherapy, } \\
\text { etc. }\end{array}$ \\
\hline
\end{tabular}

All exposures in relativity with low frequency fields received by participants of all the general public is general public exposure (ICNIRP). The most essential sources of RF-EMF exposure for the overall population are in the frequency range of $100 \mathrm{kHz}$ to $6 \mathrm{GHz}[5] .3 \mathrm{kHz}$ and 300 $\mathrm{GHz}$ associates in human health [6].

In order to protect living things especially human from the harmful environment, several studies has been piloted to identify the effect of base stations to the ambient EMR exposure. Arithmetic mean value for mobile phone base station exposure at Basel, Brussels and Amsterdam were far below the international reference level proposed by ICNIRP (International Commission on Non-Ionizing Radiation Protection) [7]. The study is more on the temporal trends of RF-EMF exposure levels in the different microenvironments of three European capitals Basel (Switzerland), Ghent and Brussels (Belgium) and establish that a rise of RF-EMF exposure levels has been observed between April 2011 and March 2012. A 
recommendation was made for a constant monitoring is needed to recognize high exposure areas and to anticipate the critical growth of RF-EMF exposure in public places [7]. At UKM, a scientific result of ratio percentage between ELF and RF location is $0.2 \%$ and $2.8 \%$ respectively and not exceed a value suggest by MCMC in accordance with INIRC/IRPA and ICNIRP [8].

In this paper, we will review the common sources of non-ionizing radiation in our everyday life and its effect towards our health. This paper also creates an awareness to the public about the harmfulness of non-ionizing radiation and future recommendation on development of policy and suitable mapping process on non-ionizing radiation exposure at Malaysia also will be stated in a section.

\section{HARMS OF NON-IONIZING RADIATION}

Human daily life always exposed by the same type of non-ionizing radiation source. Electrical and electronic equipment in general such as cordless phones, cellular, microwave ovens, computers, video games, televisions and others can create non-ionizing radiation; a low frequency radiation [9-12].

Tumor promotion by exposure to radiofrequency electromagnetic fields below exposure limits for humans. A continuous, chronic, exposure to an inclusive series of modulated radiofrequency electromagnetic fields (RF-EMF) loads all species and groups through the globe. There is still long term effect of chronic exposure to low level frequency [13-15]. EMFs Radiofrequency fields in the frequency range $300 \mathrm{MHz}$ to $300 \mathrm{GHz}$ is widely used in defense, industry, medicine, power lines and communication devices and general consumer product and is provoking risk to normal lives [15-18]. For industries, non-nuclear industries produced more ionizing radiation in comparison with nuclear industries as those non-nuclear industries get uses more on background radiation, cosmic rays [18].

Hazardous of non-ionizing radiation relying upon its ability of incident energy to penetrate to human body and absorption characteristic of different tissues. Field of radiation can change as it enters human body because human body has its own electrical properties. Central contact of low frequency time-shifting electric and attractive fields (EMF) with the human body is the 
prompting of electric fields and related streams in tissues. Likewise, presentation to low recurrence electric fields can bring about surface electric charge impacts. The EM absorption is assessed by using two parameters: the specific absorption rate (SAR) in the human head and total absorbed power by the user $[2,9,19]$. SAR is term used for body absorption rate when it is exposed to a radiofrequency electromagnetic field. International Commissions of Ionizing Radiation Protection (ICNIRP) stated $2 \mathrm{Wkg}-1$ for $10 \mathrm{~g}$ tissues of SAR as basic guidelines for public from EMF. Power absorption is electromagnetic energy that is taken up by matter refers commonly to the electron of atoms and transformed to internal energy of absorber such as thermal energy. Thermal effect and non-thermal effect are two types of interaction mechanisms of NIR with biological tissues. Exposure can cause damage by relying on an assumption from an increment of temperature above a certain threshold, there happened an effect called thermal effect [9]. Thermal effect directly occurred from tissues heating due to absorption of EMF in dissipative medium and non-thermal effect not accompanying with the increase of temperature. Temperature distribution patterns within tissue are affected by tissue permeability [13-14]

There are researches that use NIR as a subject to provide a relation between NIR and its effect on human health [20-23], and many kind of disease being related with NIR comes from physiological health effect and heavy ill effect [24-26]. United States and in residential exposed populations is one of the place that revealed ELF-EMF's are associated with cancer risk [18]. RF-EMF is said to have tumor promoting effect as it is being absorbed by tissues regardless of dose exposure [16, 27]. Exposure to transient EMF actuated the increase of NO levels, while long haul EMF has a diminishing impact on NO levels in the rodent cerebrum [19]. In human body low level of NO copes abundant physiological capacities.

Long-term exposure to low frequency EMF significantly affect sperm in terms of its motility and male's hormone also being affected [9]. 3 studies show MWR effect on fetal exposure and provided that fetuses is more vulnerable towards an exposure of microwave irradiation) [19]. Children also known as more helpless than elderly towards environmental exposures and deserves extra care to be taken into consideration [10]. 


\section{CONCLUSION}

The non-ionizing electromagnetic radiation effect was reviewed as well as it influence to human life. The exposure to electromagnetic fields could lead to changes on body tissues. This research review is expected to provide consciousness on what basically happens to everyday life if there is interference from non-ionizing electromagnetic radiation. This reviewed also will be useful to lead the way in considerate the potential human health hazards of electromagnetic radiation.

Here, in Malaysia, at the moment, there is no rule controlling exposure to EMF. There is a general national standards on EMF exposure which was released by SIRIM in February 2012 (MS-2232-1:2009) entitled "Guidelines for Limiting Exposure to Time-Varying Electric, Magnetic and Electromagnetic Fields-Part 1 : For Frequency Up to $3 \mathrm{kHz}$ ). Most of the country implements the endorsements of the guidelines issued by International Commission on Non-Ionizing Radiation Protection (ICNIRP). We suggest for a policy to be apply at Malaysia as a basic guideline for electromagnetic radiation exposure since there is no specific policy provided from government at telecommunication and industry level. Together, an implementation of mapping for electromagnetic radiation exposure at East and West of Malaysia should be done so that a reading of exposure can be present graphically and create an easiness for future researcher do a research in EMR field. This experimental section can be divided into subsections, the contents of which vary according to the subject matter of the article. It must contain all the information about the experimental procedure and materials used to carry out experiments.

\section{ACKNOWLEDGEMENTS}

This study is made possible by the usage of the grants RACE/F1/ST1/ UNISZA/15-RR 118, FRGS/1/2015/SG02/UNISZA/02/1, UM-0000033/HRU.PT.CG(CR008-2015), $68006 / 2016 / 79$ and 68006/INSENTIF/60. The authors gratefully acknowledge Universiti Sultan Zainal Abidin, Universiti Malaya and Universiti Malaysia Terengganu for the financial and experimental support of this work. Special thanks are also devoted to other researchers of Electromagnetic Research Group (EMRG) and practical students from East Coast 
Environmental Research Institute (ESERI) for their aid in this work.

\section{REFERENCES}

[1] Pennington C. Exposing America: Comparative assessments of ionizing radiation doses to U.S. populations from nuclear and non-nuclear industries. Progress in Nuclear Energy, 2007, 49(6):473-485

[2] Hidisoglu E, Kantar Gok D, Er H, Akpinar D, Uysal F, Akkoyunlu G, Ozen S, Agar A, Yargicoglu P. 2100-MHz electromagnetic fields have different effects on visual evoked potentials and oxidant/antioxidant status depending on exposure duration. Brain Research, 2016, 1635:1-11

[3] Genuis S. Fielding a current idea: Exploring the public health impact of electromagnetic radiation. Public Health, 2008, 122(2):113-124

[4] Nouh S, Elgaml N, Ali N, Khattab A, Daoud R, Amer H. Generalized electromagnetic pollution monitoring using WSN. Wireless Sensor Network, 2016, 8:85-92

[5] Calvente I, Fernández M, Pérez-Lobato R, Dávila-Arias C, Ocón O, Ramos R, Ríos-Arrabal S, Villalba-Moreno J, Olea N, Núñez M I. Outdoor characterization of radio frequency electromagnetic fields in a Spanish birth cohort. Environmental Research, 2015, 138:136-143

[6] Lin J C. Update of IEEE radio frequency exposure guidelines. IEEE Microwave Magazine, 2006, 7(2):24-28

[7] Urbinello D, Joseph W, Verloock L, Martens L, Röösli M. Temporal trends of radio-frequency electromagnetic field (RF-EMF) exposure in everyday environments across European cities. Environmental Research, 2014, 134:134-142

[8] Rahman I, Radiman S, Majid A, Yasir M, Yahaya R, Mohamed F, Noor M Z, Umar S R, Pozi F. Policy development, monitoring and subject reintroduction of nonionising radiation in Universiti Kebangsaan Malaysia. Procedia-Social and Behavioral Sciences, 2012, 59:657-662

[9] Bahaodini A, Owjfard M, Tamadon A, Jafari S M. Low frequency electromagnetic fields long-term exposure effects on testicular histology, sperm quality and testosterone levels of male rats. Asian Pacific Journal of Reproduction, 2015, 4(3):195-200 
[10] Morgan L, Kesari S, Davis D. Why children absorb more microwave radiation than adults: The consequences. Journal of Microscopy and Ultrastructure, 2014, 2(4):197-204

[11] Lerchl A, Klose M, Grote K, Wilhelm A, Spathmann O, Fiedler T, Streckert J, Hansen V, Clemens M. Tumor promotion by exposure to radiofrequency electromagnetic fields below exposure limits for humans. Biochemical and Biophysical Research Communications, 2015, 459(4):585-590

[12] Rahman N A, Mahadi W N. Measurements and simulations on ELF-EMF magnetic field exposures from multiple electric transmission lines. International Journal of Emerging Electric Power Systems, 2009, 10(4):1-20

[13] Hossain M, Faruque M, Islam M. Investigation of hand impact on PIFA performances and SAR in human head. Journal of Applied Research and Technology, 2015, 13(4):447-453

[14] Hossain M I, Faruque M R I, Islam M T. Analysis on the effect of the distances and inclination angles between human head and mobile phone on SAR. Progress in Biophysics and Molecular Biology, 2015, 119(2):103-110

[15] Prihoda T J. Genetic damage in human cells exposed to non-ionizing radiofrequency fields: A meta-analysis of the data from 88 publications (1990-2011). Mutation Research/Genetic Toxicology and Environmental Mutagenesis, 2012, 749(1):1-16

[16] Clifton-Climas S, Hale H, Reeves E, Hunt J, Englefield C, Reichelt T E, Fernandez M A, Kolupula Y R. International commission on non-ionizing radiation protection:'15 years on: Reviewing the past and looking forward'EMF and health-A global issue. Exploring appropriate precautionary approaches. Journal of Radiological Protection, 28(4):613-616

[17] Wessapan T, Rattanadecho P. Flow and heat transfer in biological tissue due to electromagnetic near-field exposure effects. International Journal of Heat and Mass Transfer, 2016, 97:174-184

[18] Mustapha A A, Owoyemi A O. Review of public health implications of cell phone radiation and other sources of non-ionizing radiation and ionizing radiation. Tropical Journal of Health Sciences, 2007, 14(1):46-52

[19] Zhang Y, Lai J, Ruan G, Chen C, Wang D. Meta-analysis of extremely low frequency electromagnetic fields and cancer risk: A pooled analysis of epidemiologic studies. 
Environment International, 2016, 88:36-43

[20] Baliatsas C, Bolte J, Yzermans J, Kelfkens G, Hooiveld M, Lebret E, van Kamp I. Actual and perceived exposure to electromagnetic fields and non-specific physical symptoms: An epidemiological study based on self-reported data and electronic medical records. International Journal of Hygiene and Environmental Health, 2015, 218(3):331-344

[21] Choi Y J, Choi Y S. Effects of electromagnetic radiation from smartphones on learning ability and hippocampal progenitor cell proliferation in mice. Osong Public Health and Research Perspectives, 2016, 7(1):12-17

[22] Martens A L, Bolte J F, Beekhuizen J, Kromhout H, Smid T, Vermeulen R C. Validity of at home model predictions as a proxy for personal exposure to radiofrequency electromagnetic fields from mobile phone base stations. Environmental Research, 2015, $142: 221-226$

[23] Repacholi M H. Health risks from the use of mobile phones. Toxicology Letters, 2001, 120(1):323-331

[24] Altunkaynak B Z, Altun G, Yahyazadeh A, Kaplan A A, Deniz O G, Türkmen A P, Önger M E, Kaplan S. Different methods for evaluating the effects of microwave radiation exposure on the nervous system. Journal of Chemical Neuroanatomy, 2016, 75:62-69

[25] Del Vecchio G, Giuliani A, Fernandez M, Mesirca P, Bersani F, Pinto R, Ardoino L, Lovisolo G A, Giardino L, Calzà L. Continuous exposure to 900MHz GSM-modulated EMF alters morphological maturation of neural cells. Neuroscience Letters, 2009, 455(3):173-177

[26] Kaplan S, Deniz O G, Önger M E, Türkmen A P, Yurt K K, Aydın I, Altunkaynak B Z, Davis D. Electromagnetic field and brain development. Journal of Chemical Neuroanatomy, 2016, 75:52-61

[27] Foster K R, Chou C K. Are children more exposed to radio frequency energy from mobile phones than adults? IEEE Access, 2014, 2:1497-1509

\section{How to cite this article:}

Syaza SKF, Umar R, Hazmin SN, Kamarudin MKA, Hassan A, Juahir H.Non-ionizing radiation as threat in daily life. J. Fundam. Appl. Sci., 2017, 9(2S), 308-316. 